\title{
Electrocatalytic and Magnetic Properties of Ultrathin Nanostructured Iron-Melanin Films on Au(111)
}

\author{
Alejandro González Orive, ${ }^{[b]}$ Patricio Dip, ${ }^{[c]}$ Yurima Gimeno, ${ }^{[b]}$ Pilar Díaz, ${ }^{[b]}$ \\ Pilar Carro, ${ }^{[b]}$ Alberto Hernández Creus, ${ }^{b]}$ Guillermo Benítez, ${ }^{[a]}$ Patricia L. Schilardi, ${ }^{[a]}$ \\ Leandro Andrini, ${ }^{[\mathrm{a}]}$ Felix Requejo, ${ }^{[\mathrm{a}]}$ and Roberto C. Salvarezza*[a]
}

\begin{abstract}
We have prepared ultrathin, nanostructured melanin films on $\mathrm{Au}-$ (111) by means of electrochemical selfassembly. These films were characterized by using Auger electron spectroscopy, X-ray absorption near-edge structure spectroscopy, scanning tunneling microscopy, magnetic force microscopy, and electrochemical techniques. Two types of nanostructures are
\end{abstract}

present in the film: melanin nanoparticles and $\mathrm{Fe}_{3} \mathrm{O}_{4}$ nanoparticles. The melanin nanoparticles contain $\mathrm{Fe}$ bonded to oxygen-containing phenolic groups in an octahedral configuration similar

Keywords: biosensors - catalysis • magnetic properties • melanins nanostructures to that found in $\mathrm{Fe}_{2} \mathrm{O}_{3}$. The inorganicorganic composite exhibits magnetic properties and catalyzes the electroreduction of hydrogen peroxide in alkaline and neutral electrolyte solutions. The electrocatalytic activity depends on the Fe-bound melanin and appears to be similar to that found for Fe-porphyrins.

\section{Introduction}

Melanins are complex biopolymers that are widely distributed in living organisms. The most widespread, eumelanin, comprises molecular species derived from the coupling of 5,6-dihydroxyindole (DHI) and 5,6-dihydroxyindole-2-carboxylic acid (DHICA) monomers, which aggregate and form granules. ${ }^{[1]}$ The secondary structure of melanins is still under debate. However, compelling evidence suggests that melanin is formed by small nanometer-sized particles that aggregate to form hierarchical structures. ${ }^{[2]}$

[a] Dr. G. Benítez, Dr. P. L. Schilardi, Lic. L. Andrini, Dr. F. Requejo, Dr. R. C. Salvarezza

Instituto de Investigaciones Fisicoquímicas Teóricas y Aplicadas (INIFTA), Facultad de Ciencias Exactas

Universidad Nacional de La Plata-CONICET

Sucursal 4 Casilla de Correo 16, (1900) La Plata (Argentina)

Fax: (+54) 221-425-4642

E-mail: robsalva@inifta.unlp.edu.ar

[b] Lic. A. González Orive, Dr. Y. Gimeno, Dr. P. Díaz, Dr. P. Carro, Dr. A. Hernández Creus

Departamento de Química Física, Facultad de Química Universidad de La Laguna, 38071 La Laguna, Tenerife (Spain)

[c] Ing. P. Dip

Escuela de Postgrado, Facultad de Ciencias Físicas y Matemáticas Universidad de Chile, Beauchef 850, Casilla 2777, Santiago (Chile)
Melanin exhibits interesting properties such as photoactivity and semiconducting behavior, among others. ${ }^{[3]}$ The electrochemical activity of different kinds of melanin adsorbed on electrode surfaces was also described in recent papers. ${ }^{[4]}$ Therefore, melanin is interesting from the point of view of materials science. Melanin is able to trap large amounts of cations such as $\mathrm{Cu}, \mathrm{Al}, \mathrm{Zn}$, and $\mathrm{Fe} \cdot{ }^{[5]}$ In the brain melanin is commonly associated with iron. ${ }^{[6]}$ Little is known about the state of aggregation of iron in melanins. ${ }^{[7]} \mathrm{X}$-ray absorption fine-structure and infrared spectroscopic studies suggested that iron in neuromelanin is bonded to oxygen from phenolic groups in an octahedral configuration. ${ }^{[7]}$

It has been reported that the melanin-redox-active-metal systems have peroxidase activity, which promotes the formation of reactive oxygen species. ${ }^{[8]}$ Structural changes in melanin nanoparticles during peroxide bleaching have also been reported. ${ }^{[9]}$ Lipid peroxidation in the substancia nigra region of the brain has been related to Parkinson's disease. ${ }^{[10]}$ Thus, the evaluation of the peroxidase activity of the Fe-melanin system is important for the understanding of pathogenesis in Parkinson's disease.

Hydrogen peroxide is produced under a variety of circumstances. Activated lymphocytes release hydrogen peroxide as part of an oxidative burst as a means to kill bacteria. ${ }^{[11]}$ Several enzymatic reactions produce $\mathrm{H}_{2} \mathrm{O}_{2}$ as a byproduct, while other reactions consume the molecule. The rate of mitochondrial $\mathrm{H}_{2} \mathrm{O}_{2}$ release was found to be associated with 
life expectancy or the physiological age of organisms rather than the chronological age. ${ }^{[12]}$ In this context there is also interest to develop biosensors to detect and to quantify the amount of hydrogen peroxide in living organisms.

Electrocatalytic properties of Fe-containing organic molecules have also attracted considerable interest in recent years. In particular, $\mathrm{Fe}^{\mathrm{III}}$-porphyrins play a crucial role in biological functions such as electron transfer, oxygen transport, and catalyzing oxygen incorporation into other molecules. In these materials, the catalytic properties are related to the presence of $\mathrm{Fe}^{\mathrm{III}}$ bound in octahedral configurations. $\mathrm{Fe}$-porphyrins on gold have been characterized at the molecular level. Their electrochemical and electrocatalytic properties in relation to oxygen and hydrogen peroxide electroreduction have been carefully investigated. ${ }^{[13]}$ In contrast, Fe-containing melanins, which could also be potentially important materials in electrocatalysis and bioelectrocatalysis, remain understudied.

We have recently reported a novel method for the electrochemical self-assembly of melanin films on $\mathrm{Au}(111)$ from synthetic eumelanins. ${ }^{[14]}$ Unlike other electrochemical methods that involve oxidation of monomers, ${ }^{[4]}$ these films are produced under cathodic polarization in a melanin-containing aqueous $0.1 \mathrm{~m} \mathrm{NaOH}$ solution. In this case, melanin selforganizes under electrochemical potential control into a hierarchical structure similar to those reported for different kinds of natural melanin. Therefore, these films could act as biomimetic systems that can be subjected to different types of studies. In particular, those studies related to electrochemical properties could have a potential impact in areas ranging from biology to nanotechnology.

In this work we explore the electrochemical and magnetic properties of Fe-containing, nanostructured ultrathin melanin films electrochemically self-assembled on $\mathrm{Au}(111)$. We found that inorganic-organic composites are formed during the electrochemical self-assembly. Results show that the films contain both $\mathrm{Fe}$-melanin nanoparticles and $\mathrm{Fe}_{3} \mathrm{O}_{4}$ nanoparticles. This material exhibits magnetic properties and catalyzes hydrogen peroxide electroreduction in neutral and alkaline solutions. The electrocatalytic activity of the films is related to the $\mathrm{Fe}$ ion coordinated to the cathecol units in an octahedral configuration, as concluded by comparison with $\mathrm{Fe}$-containing porphyrins polymerized on $\mathrm{Au}-$ (111), which exhibit similar electrocatalytic activity. On the other hand, the magnetic properties appear to be mainly related to the $\mathrm{Fe}_{3} \mathrm{O}_{4}$ nanoparticles trapped in the organic matrix.

\section{Experimental Section}

Melanin films were grown by electrochemical self-assembly as described in ref. [14]. Briefly, this procedure consists of the immersion of a preferentially oriented $\mathrm{Au}(111)$ substrate (Arrandee TM 45 Berliner Glass KG, Germany) in a synthetic melanin-containing aqueous $0.1 \mathrm{~m} \mathrm{NaOH}$ solution (0.3 and $0.03 \mathrm{gL}^{-1}$, melanin from Sigma, M8631). For the more concentrated solution $0.28 \mathrm{ppm}$ of Fe was determined by atomic absorption spectroscopy. The Au electrodes were polarized in a conventional three- electrode electrochemical cell for a time $t_{\mathrm{a}}$ at $-1.0 \mathrm{~V}$ (saturated calomel electrode, SCE) in the working solution to grow melanin films. ${ }^{[14]}$ The melanin-covered $\mathrm{Au}$ electrodes were then removed from the cell, carefully cleaned with MilliQ water, and dried under argon before characterization.

The surface composition of the films was studied by using Auger electron spectroscopy (AES). The Auger spectra were taken in the derivative mode $(\mathrm{d} N / \mathrm{d} E)$ with a single-pass cylindrical mirror analyzer (CMA, Physical Electronics 10-155) using a $4 \mathrm{eV}$ peak-to-peak modulation amplitude and a $15 \mathrm{eVs}^{-1}$ scanning rate, and exciting the sample with $3 \mathrm{keV}$ electrons $\left(10 \mathrm{~mA} \mathrm{~cm}^{-2}\right)$.

X-ray absorption near-edge structure spectroscopy (XANES) was also used to characterize the sample. The X-ray absorption spectra were measured at the XANES beamline of the LNLS, Laboratorio Nacional do Luz Síncrotron, Campinas, Sao Paulo, Brazil. XANES spectra at the Fe K-edge $(7112 \mathrm{eV})$ for a pure melanin sample was recorded in air at room temperature in transmission mode with three ion chambers as detectors: one before the sample to measure the incident X-ray intensity $\left(I_{0}\right)$, one after the sample and before the corresponding reference metal foil to measure the intensity after the sample $\left(I_{1}\right)$, and one after the metal foil $\left(I_{2}\right)$. The sample and the metal foil spectra were expressed as $\log \left(I_{0} / I_{1}\right)$ and $\log \left(I_{1} / I_{2}\right)$, respectively. The corresponding spectrum from the metal foil was used to calibrate the absolute energy scale for the corresponding sample spectrum by positioning the absorption edge at the first inflection point. Monochromators on the beamlines were equipped with $\mathrm{Si}(111)$ crystals. The $0.3 \mathrm{~mm}$ vertical aperture of the beam definition slit in the hutch provided a resolution of about $2.5 \mathrm{eV}$ at the Fe K-edge. X-ray absorption data for melanin supported on $\mathrm{Au}(111)$ was obtained by using the total electron yield (TEY) mode. The sample was mounted in a chamber with kapton windows filled with $\mathrm{He}$ at atmospheric pressure. The current signal for the energy of each incident photon was obtained by using a positively biased collector under the ionized $\mathrm{He}$ atmosphere.

Data reduction: X-ray absorption data were analyzed by using standard procedures. $^{[15]}$ A linear background was fit to the pre-edge region and then subtracted from the entire spectrum, and the jump of the spectrum was normalized to unity with the post-edge asymptotic value. To obtain the mean oxidation state of the metal in each sample, the edge shift relative to the metal reference compound was determined following the method proposed by Capehart et al. ${ }^{[15 a]}$ This method is based on the integration of the normalized absorption spectra for an interval extending from well below the edge up to the first value of energy for which the normalized absorption of the reference is equal to one $\left(E_{\mathrm{R}}\right)$. Thus, the integrated absorption of the sample is obtained by integrating up to the energy $E_{\mathrm{S}}$, with $E_{\mathrm{S}}$ having such a value that the integrated area of the sample and reference absorption are equal (the white line contribution to the normalized absorption area was eliminated by taking $80 \%$ of the integrated absorption area of the reference). Therefore, the edge shift in the XANES spectrum is given by $\Delta E=E_{\mathrm{S}}-E_{\mathrm{R}}$. This method is independent of the fine structure, namely, the occurrence of certain peaks or shoulders in the raising edge, contrary to what happens with the simple determination of the inflection points. The position of the edge is related to the oxidation state of the elements in such a way that the edge energy shifts vary monotonically with the valence of the metal atom. ${ }^{[15 b]}$ In a set of chemically similar compounds, a linear relationship has been shown to exist between the energy shift and the oxidation state. ${ }^{[15 c]}$ This is true in a model in which the energy shift of the core level is mainly due to Coulombic effects. ${ }^{[15 d]}$ Therefore, we performed a linear fit of the oxidation state as a function of the energy shift of different standard bulk oxide compounds corresponding to the same element. These fits were used to find the mean oxidation state for $\mathrm{Fe}$ species bonded to oxygen in the melanin samples from the edge energy shift determined by using Capehart's method.

Film structures were determined by scanning tunneling microscopy (STM) operating in the topographic mode at a bias voltage of $\approx 1-2 \mathrm{~V}$, tunneling current of $\approx 0.5 \mathrm{nA}$, and at scan rates of $0.5-1.5 \mathrm{~Hz}$. PtIr tips were used in these measurements. Magnetic force microscopy (MFM) images (lift mode) taken at a scanning rate of $1 \mathrm{~Hz}$ with probes coated 
with magnetic $\mathrm{CoCr}$ film were used at a drive frequency of $61 \mathrm{kHz}$. A lift height of 50-100 nm was used to prevent any topographic effect. Probes and samples were magnetized by using an external 0.3 tesla magnetic field.

Electrochemical characterization was performed in $\mathrm{NaOH}(0.1 \mathrm{M})$ or in phosphate buffer pH $7.0\left(\mathrm{Na}_{2} \mathrm{HPO}_{4}, \mathrm{KH}_{2} \mathrm{PO}_{4}\right)$, with and without $\mathrm{H}_{2} \mathrm{O}_{2}$ addition. Electrolyte solutions were prepared with analytical grade chemicals and bubbled with purified nitrogen for $2 \mathrm{~h}$ before the electrochemical investigations.

The electrochemical behavior of the biopolymer-covered $\mathrm{Au}(111)$ was compared with those exhibited by polymeric films of Fe-tetra-3-aminophenylporphyrin ( $\left.\mathrm{Fe}^{\mathrm{III}}-\mathrm{TAPP}\right)$ and TAPP on $\mathrm{Au}(111)$. Thin films of TAPP and TAPP-(Fe ${ }^{\text {III }}$ chloride) (MidCentury $\mathrm{Co}$ ) were prepared by electropolymerization. ${ }^{[16]}$ The electropolymerization was carried out by means of consecutive potential cycles at $0.2 \mathrm{~V} \mathrm{~s}^{-1}$ between -1.6 and $1.5 \mathrm{~V}$ in a $N, N^{\prime}$-dimethylformamide (DMF) + tetrabutylammonium perchlorate solution $(0.1 \mathrm{M})$ containing either $0.1 \mathrm{~mm}$ TAPP- $\left(\mathrm{Fe}^{\mathrm{III}}\right.$ chloride) or $0.1 \mathrm{~mm}$ TAPP. TAPP and TAPP- $\left(\mathrm{Fe}^{\mathrm{III}}\right.$ chloride) were used without further purification. DMF (Fluka p.a. $>99.5 \%$ ) was treated with anhydrous $\mathrm{Na}_{2} \mathrm{CO}_{3}$ and then doubly distilled at reduced pressure under an argon atmosphere. Tetrabutylammonium perchlorate (Fluka, $99 \%$ ) was recrystallized from a 2:1 ethanol/water solution and dried at $60^{\circ} \mathrm{C}$ under vacuum. The electrolyte solutions were purged with argon and kept at room temperature for all the experiments. After the polymerization, the modified electrodes were carefully rinsed with DMF and then with Milli-Q water.

\section{Results and Discussion}

AES characterization: A Typical AES spectrum for a melanin film grown for $t_{\mathrm{a}}=100 \mathrm{~min}$ on $\mathrm{Au}$ is shown in Figure 1a (spectrum I). The N/C ratio was $\approx 0.15-0.18$, similar to those reported for different kinds of melanins. ${ }^{[17]}$ The evolution of the N/Au ratio with $t_{\mathrm{a}}$ reflects the increase in the film thickness (Figure 1b). In fact, for large $t_{\mathrm{a}}$ values the Au signal disappears, which indicates that the substrate is completely covered by the organic film.

Spectrum I shown in Figure 1a also indicates the presence of $\mathrm{Fe}$ in the Au-supported melanin film. In fact, Figure $1 \mathrm{~b}$ shows that both the $\mathrm{N}$ and Fe signals increase simultaneously with $t_{\mathrm{a}}$. For thicker films $\left(t_{\mathrm{a}}=840 \mathrm{~min}\right)$ where the $\mathrm{Au}$ signal does not interfere, the Fe MVV transition at $55 \mathrm{eV}$ is characteristic of oxygen-bound $\mathrm{Fe}$ (Figure 1a, spectrum III). ${ }^{[18]}$ The $\mathrm{Fe} / \mathrm{N}$ ratio derived from the spectra of the melanin film is $\approx 3$, a figure that largely exceeds that expected for Fe-bound melanin. ${ }^{[19]}$ It has been reported that the maximum $\mathrm{Fe} / \mathrm{N}$ ratio expected for melanin is close to 0.25 . Figure 1a (IV) shows the Auger spectrum of a melanin film on $\mathrm{Au}$ evaporated from a methanolic solution. In this case the $\mathrm{Fe} / \mathrm{N}$ ratio is $<1$. These results strongly support the fact that iron oxide species are deposited during the self-assembly process. Further evidence for the presence of iron oxide was obtained by acid treatment of the Au-supported melanin films. In fact, after acid cleaning in $0.1 \mathrm{M} \mathrm{H}_{2} \mathrm{SO}_{4}$ for $1 \mathrm{~min}$ (Figure 1a, spectrum II) the Fe signals practically disappear and the $\mathrm{O}$ signal is markedly reduced, while no significant changes in the $\mathrm{C}$ and $\mathrm{N}$ signals are observed. This means that iron oxide species were selectively dissolved in acids. This is a clear indication that iron oxide species are also deposited during melanin film growth.
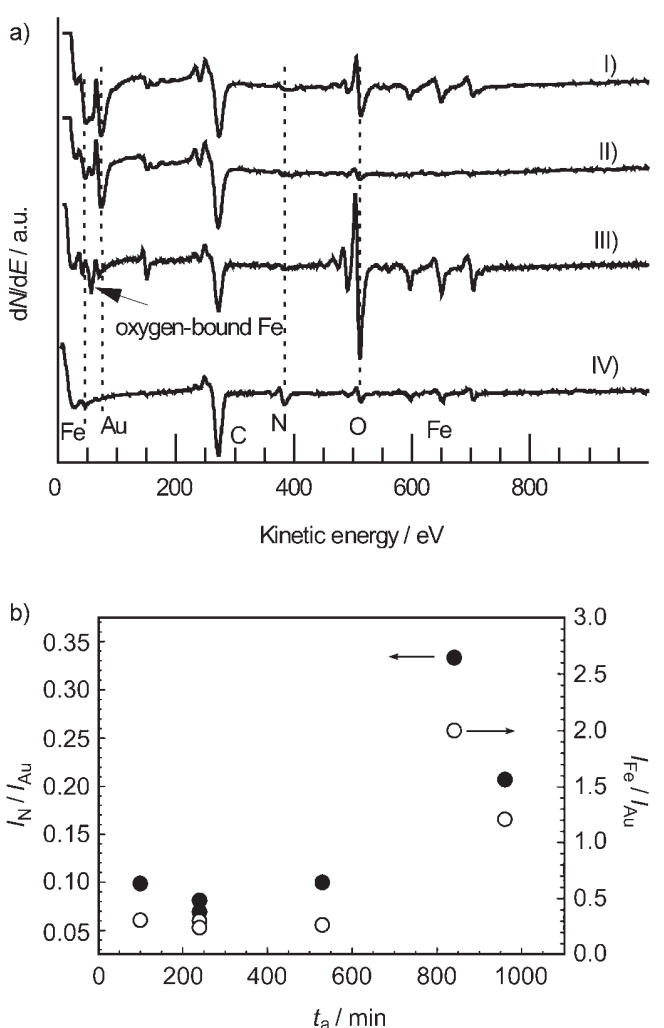

Figure 1. a) AES spectra: I) for melanin films electrochemically grown for $t_{\mathrm{a}}=100 \mathrm{~min}, E=-1.0 \mathrm{~V}, c=0.3 \mathrm{gL}^{-1}$. C, N, O, and Fe signals are indicated; II) after acid cleaning in $\mathrm{H}_{2} \mathrm{SO}_{4}(0.1 \mathrm{M})$ for $1 \mathrm{~min}$; III) for a melanin film electrochemically grown for $t_{\mathrm{a}}=14 \mathrm{~h}, E=-1.0 \mathrm{~V}, c=0.3 \mathrm{~g} \mathrm{~L}^{-1}$; IV) of an evaporated melanin film (methanolic solution) on Au. b) Plots

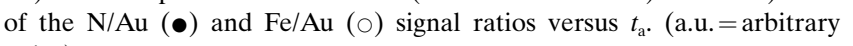
units.)

XANES characterization: In the present work, XANES spectra were used as a fingerprint method to determine the nature of the species located in solid melanin and Au-supported melanin films, and to rule out the presence of specific Fe environments and their oxidation states. In fact, XANES can be used as a "fingerprint" technique if reference samples are employed for comparison. It allows the identification of unknown species or atomic sites, even for diluted systems. This is possible due to the nature of XANES, which is sensitive to the electronic configuration of the absorber atom and to the spatial arrangement of atoms around it. ${ }^{[20]}$ The near-edge structure in an absorption spectrum is loosely defined as the range between the threshold energy and the point at which the extended X-ray absorption fine structure begins, and it typically extends $50-100 \mathrm{eV}$ above the X-ray absorption edge. Fe K-edge XANES spectroscopy has previously been successfully used to determine the oxidation state of Fe in diluted Fe centers. ${ }^{[21]}$

Figure 2 shows the Fe K XANES spectra of melanin samples (solid melanin and Au-supported melanin films, $E=$ $\left.-1.0 \mathrm{~V}, t_{\mathrm{a}}=24 \mathrm{~h}, c=0.3 \mathrm{~g} \mathrm{~L}^{-1}\right)$ and Fe oxide reference compounds: $\mathrm{FeO}\left(\mathrm{Fe}^{2+}\right), \mathrm{Fe}_{3} \mathrm{O}_{4}\left(\mathrm{Fe}^{2+}\right.$ and $\left.\mathrm{Fe}^{3+}\right)$, and $\mathrm{Fe}_{2} \mathrm{O}_{3}$ $\left(\mathrm{Fe}^{3+}\right)$. Figure 3 shows the average chemical shift of the ab- 


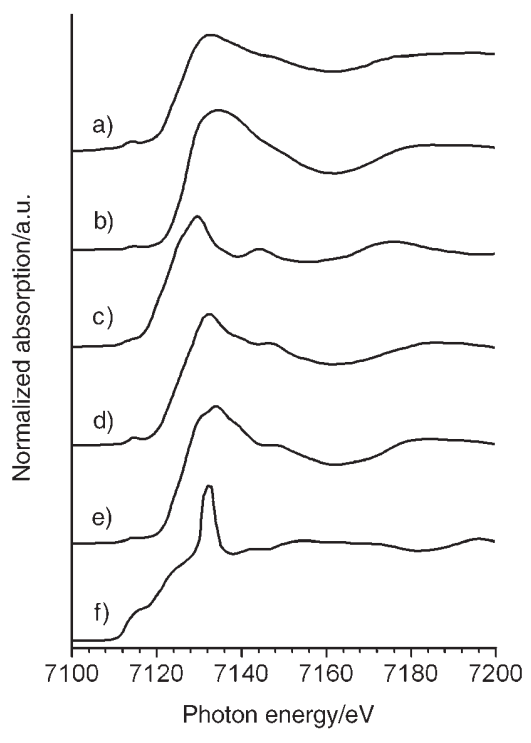

Figure 2. Fe K-edge XANES spectra of a) Au-supported melanin film on $\operatorname{Au}(111)\left(E=-1.0 \mathrm{~V}, t_{\mathrm{a}}=24 \mathrm{~h}, c=0.3 \mathrm{gL}^{-1}\right)$; b) solid melanin; c) $\mathrm{FeO}$; d) $\mathrm{Fe}_{3} \mathrm{O}_{4}$; e) $\mathrm{Fe}_{2} \mathrm{O}_{3}$; f) metallic $\mathrm{Fe}$ (film). A qualitative analysis allows the assignment of the Fe state in melanin samples by comparison with oxide reference compounds (see text).

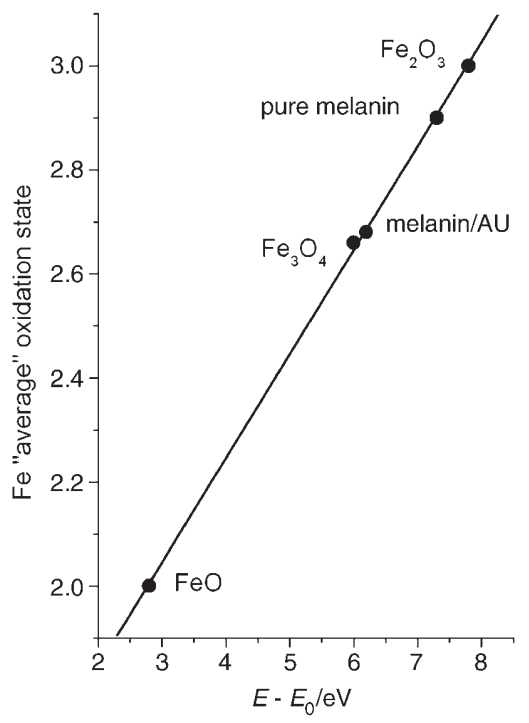

Figure 3. Energy shift of Fe K-edge in relation to metallic Fe $\left(E_{0}\right)$. Oxide compounds are taken as the reference for "average" oxidation state calibration. Average oxidation state of Fe in solid melanin clearly differs between bulk state and Au-supported melanin (see Table 1 for numeric values of shifting)

sorption Fe K-edge for all compounds shown in Figure 2. In the following we refer to Fe oxidation states as "average" oxidation states as our XANES experiments represent an averaged value weighted by atomic (or site) abundance of each type of Fe ion in each sample.

The higher the oxidation state of the metal, the more positive the overall charge of the atom, and more energy is required to excite an electron out of an orbital. ${ }^{[22]}$ The first formally allowed electric dipole transition is the $1 \mathrm{~s} \rightarrow 4 \mathrm{p}$ transition. Due to the size of the $4 p$ orbital, it overlaps with $p$ orbitals of the ligands, either through $\pi$ or $\sigma$ bonding. Consequently, this transition is sensitive to the oxidation state and the ligand environment of the metal. For certain symmetries around the metal, the formally electric-dipole-forbidden $1 \mathrm{~s} \rightarrow 3 \mathrm{~d}$ transition can be observed, which occurs at a lower energy than the main edge transitions. ${ }^{[23]}$ This transition gains intensity due to the mixing of metal $3 \mathrm{~d}$ and $4 \mathrm{p}$ orbitals, and provides information about the ligand as well as about the oxidation state and symmetry of the metal complex. ${ }^{[24]}$ This "orbital mixing" is favored in octahedral environments, which can be easily distorted compared with higher symmetric tetrahedral environments. The case of $\mathrm{Fe}^{2+}$ and $\mathrm{Fe}^{3+}$ is a clear example of tetrahedral and octahedral environments, respectively, and illustrate this concept through the intensity of the peak at approximately $7114 \mathrm{eV}$ at the pre-edge absorption region.

Figure 2 clearly shows that the average Fe state in the Ausupported melanin differs from the bulk one (spectra a and $\mathrm{b}$, respectively). In addition, similarities between the melanin samples and reference compounds are observed. In effect, the XANES spectrum of pure melanin exhibits similar general features and pre-peak characteristics to the $\mathrm{Fe}_{2} \mathrm{O}_{3}$ spectrum (see spectra $\mathrm{b}$ and e, respectively). This type of similarity is also observed between spectra corresponding to Au-supported melanin and $\mathrm{Fe}_{3} \mathrm{O}_{4}$ (see spectra a and d, respectively). In general, the matching between samples and reference compounds is not complete because of the different nature of the compounds: whereas Fe in melanin samples is highly diluted, reference compounds have concentrated $\mathrm{Fe}$ in crystalline systems. Moreover, unlike in pure $\mathrm{Fe}$ oxides, $\mathrm{Fe}$ in the proposed structure for synthetic melanin is an iron atom coordinated to two pairs of oxygen atoms that are part of two quinone-like structures in melanin. ${ }^{[19,25]}$

The same trend is observed by simple inspection of the energy shift of the Fe K-edge (Figure 2). Relative concentrations of $\mathrm{Fe}^{2+}$ and $\mathrm{Fe}^{3+}$ can be obtained by measuring the energy shift at the absorption edge. With this value (obtained as it was indicated in the Experimental Section), the relative concentration of $\mathrm{Fe}$ species in melanin films on $\mathrm{Au}-$ (111) is estimated by considering the XANES spectra (spectra $\mathrm{a}$ and $\mathrm{b}$ in Figure 2) as a linear superposition from only two different absorbing $\mathrm{Fe}$ sites: $\mathrm{Fe}^{2+}$ in $\mathrm{Fe}_{3} \mathrm{O}_{4}$ and $\mathrm{Fe}^{3+}$ in melanin. The energy edge position, $\mathrm{Fe}^{2+} / \mathrm{Fe}^{3+}$ ratios and the relative concentration estimated for Fe species is showed in Table 1. As in the previous analysis of the Fe species, derived from the qualitative inspection of the pre-peak and the general features of the spectra, $\mathrm{Fe}$ in solid melanin is more similar to $\mathrm{Fe}_{2} \mathrm{O}_{3}$ (hematite) than to any other iron oxide, while the $\mathrm{Fe}$ environment in $\mathrm{Au}$-supported melanin is very close to that found in $\mathrm{Fe}_{3} \mathrm{O}_{4}$ (magnetite). Thus, the main $\mathrm{Fe}$ species in $\mathrm{Au}$-supported melanin is magnetite-like $(\approx 80 \%)$ and other $\mathrm{Fe}$ species remaining in melanin are just a minor component $(\approx 20 \%)$. A discussion of this relationship is given below for the Au-supported melanin structure. 
Table 1. Energy edge positions for Fe reference compounds and melanin samples. The $\mathrm{Fe}^{2+} / \mathrm{Fe}^{3+}$ ratio derived from XANES data (Figure 3) and relative concentration of magnetite-like species in the samples are also indicated.

\begin{tabular}{lclc}
\hline Sample & $\begin{array}{c}\text { Energy edge } \\
\text { position [eV] }\end{array}$ & $\begin{array}{l}\mathrm{Fe}^{2+} / \mathrm{Fe}^{3+} \\
\text { ratio }\end{array}$ & $\begin{array}{l}\mathrm{Fe}_{3} \mathrm{O}_{4} \text { relative } \\
\text { concentration [\%] }\end{array}$ \\
\hline $\mathrm{FeO}$ & 7120.6 & 1 & - \\
$\mathrm{Fe}_{3} \mathrm{O}_{4}$ & 7125.0 & 0.5 & 100 \\
$\mathrm{Fe}_{2} \mathrm{O}_{3}$ & 7127.3 & 0 & - \\
solid melanin & 7127.0 & 0 & 0 \\
Au-supported & 7125.4 & 0.37 & 80 \\
melanin film & & & \\
\hline
\end{tabular}

STM and MFM characterization: STM images of the films grown at $E=-1.0 \mathrm{~V}, t_{\mathrm{a}}=100 \mathrm{~min}$, and $c=0.3 \mathrm{~g} \mathrm{~L}^{-1}$ (Figure $4 \mathrm{a}, \mathrm{b}$ ) show $40-60 \mathrm{~nm}$ granules formed by $3-8 \mathrm{~nm}$-sized nanoparticles, which also cover the substrate (Figure $4 \mathrm{~b}$ ). As already discussed, the film structure cannot be related to a simple electrodeposition process as it exhibits the hierarchical structure found in natural melanins. ${ }^{[14]}$ The fine structure of the large granules is also observed for the films after acid cleaning (Figure 4c). However, some granules and nanoparticles that cover the Au substrate in Figure $4 \mathrm{~b}$ have been removed so that the triangular terraces of $\mathrm{Au}(111)$ are now clearly observed. The nanometer-size thickness of these films is clearly revealed in these images.

We have used MFM to detect iron-rich granules in the melanin film (Figure 5). Figure 5a shows melanin granules imaged in the topographic mode, whereas Figure $5 b$ corresponds to the phase shift of the oscillating magnetic cantilever (operating in the lift mode).

It is evident that defined magnetic fields are concentrated in some granules while they are too weak in others, irrespective of the topography. It is reasonable to assume that granules with higher contrast are formed by $\mathrm{Fe}_{3} \mathrm{O}_{4}$ nanoparticles, as already determined by XANES data. The film structure can be used to understand the relative amount of Fe species estimated from the XANES characterization. The main $\mathrm{Fe}$ species in Au-supported melanin is a magnetite-like species $(\approx 80 \%)$, while those $\mathrm{Fe}$ species remaining in the same state as they exist in pure melanin form just a minor component ( $\approx 20 \%$ ). Taking into account that the fine structure of the film is composed of 6-8 nm melanin nanoparticles containing 16-30 protomelanin units, ${ }^{[14]}$ and that each protomelanin unit binds an $\mathrm{Fe}$ atom, ${ }^{[19]}$ the maximum number of $\mathrm{Fe}$ atoms per melanin nanoparticle is $\approx 20-30$. On the other hand, a $8 \mathrm{~nm} \mathrm{Fe}_{3} \mathrm{O}_{4}$ nanoparticle contains $\approx 1000 \mathrm{Fe}$ atoms. There-
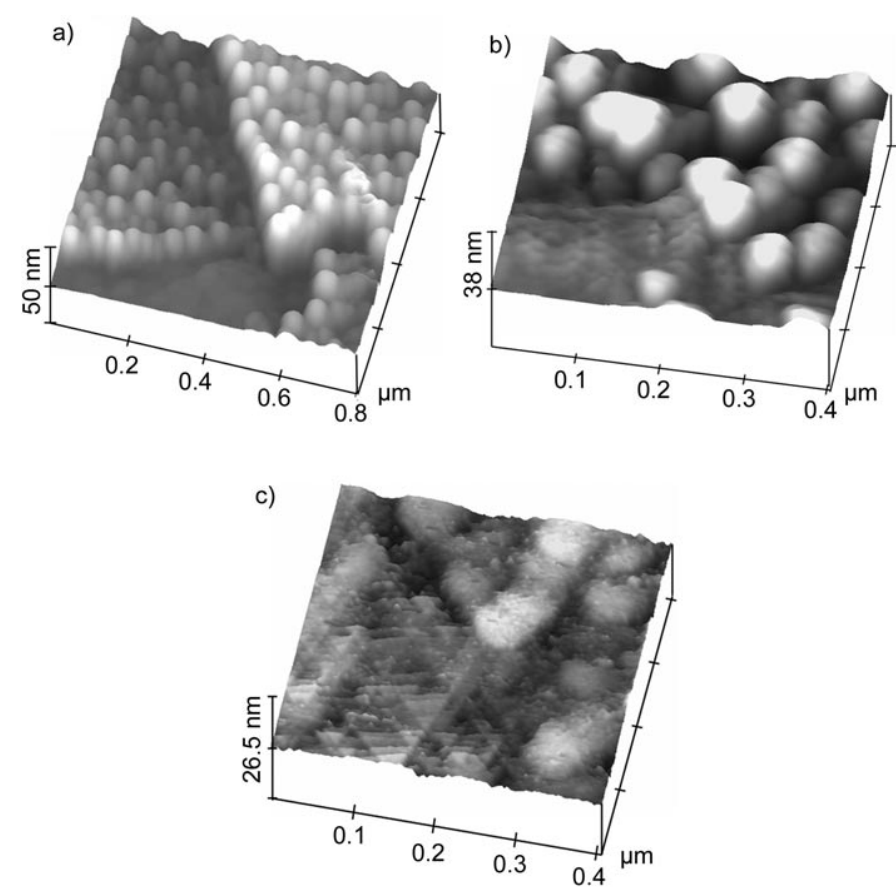

Figure 4. STM images of a melanin film ( $E=-1.0 \mathrm{~V}, c=0.3 \mathrm{gL}^{-1}, t_{\mathrm{a}}=$ $100 \mathrm{~min}$ ) showing a) melanin granules $40-60 \mathrm{~nm}$ in size and b) the film structure at higher magnification. Small particles in the large granules and covering the substrate are observed; c) STM image of the film after acid cleaning.

Figure $5.600 \times 600 \mathrm{~nm}^{2}$ MFM images of the melanin film $\left(E=-1.0 \mathrm{~V}, c=0.3 \mathrm{~g} \mathrm{~L}^{-1}, t_{\mathrm{a}}=30 \mathrm{~min}\right)$ : a) topographic image; b) phase image (lift mode). Different magnetized granules are visible through the relative size and intensity of the green zones. The white arrows in (a) show large granules that have no intense magnetic counterparts in (b). The yellow arrows in (a) and (b) indicate small granules that exhibit magnetic properties. 
sorbed and stored into the film. In fact, iron oxide nanoparticles can be synthesized by coprecipitation of $\mathrm{Fe}^{3+}$ and $\mathrm{Fe}^{2+}$ in $\mathrm{NaOH}$ solutions. ${ }^{[26]}$

Electrochemical characterization: Figure 6 shows voltammograms recorded at $0.02 \mathrm{~V} \mathrm{~s}^{-1}$ for Au-supported melanin electrodes $\left(E=-1.0 \mathrm{~V}, c=0.03 \mathrm{gL}^{-1}\right)$ in $0.1 \mathrm{~m} \mathrm{NaOH}$ for $t_{\mathrm{a}}=$ $100 \mathrm{~min}$ and $t_{\mathrm{a}}=24 \mathrm{~h}$ (Figure 6a and $\mathrm{b}$, respectively). As al-

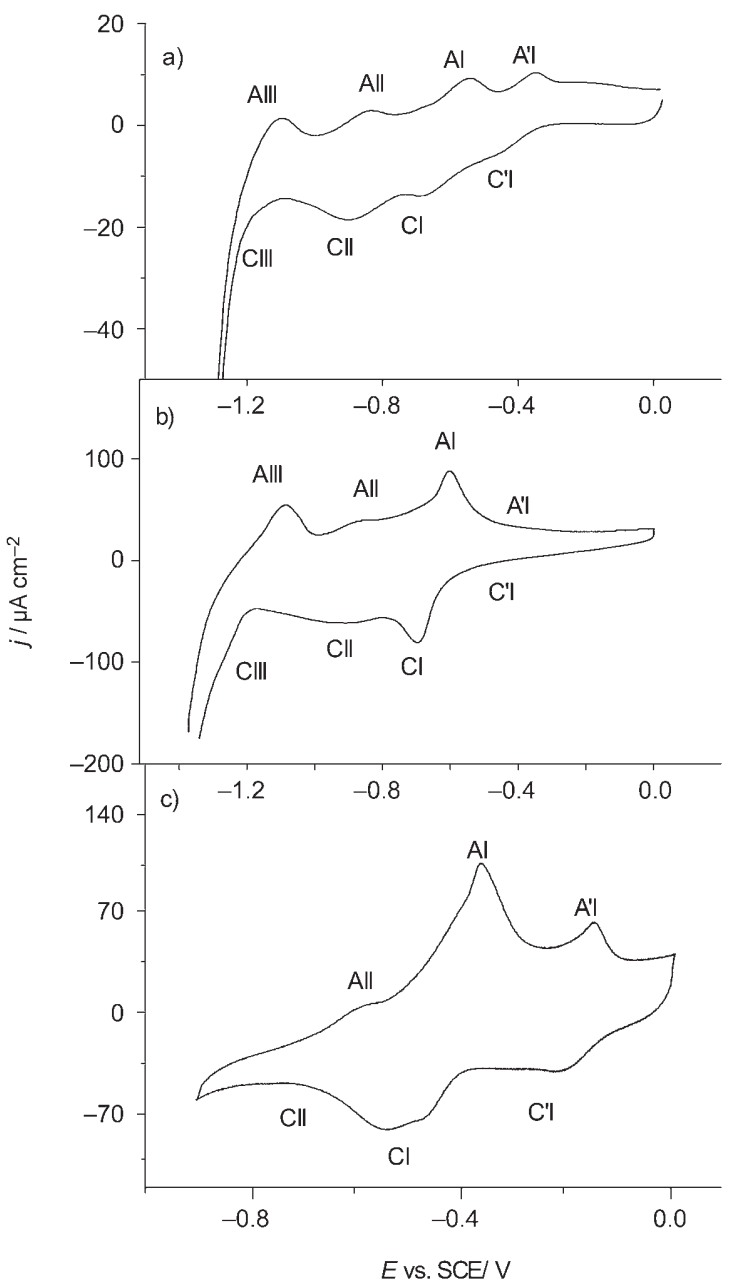

Figure 6. Typical stabilized voltammograms for $\mathrm{Au}(111)$-supported melanin films $\left(E=-1.0 \mathrm{~V}, c=0.03 \mathrm{~g} \mathrm{~L}^{-1}\right)$ recorded in $\mathrm{NaOH}(0.1 \mathrm{M})$ at $0.02 \mathrm{~V} \mathrm{~s}^{-1}$ from 0.0 to $-1.3 \mathrm{~V}$ for a) $t_{\mathrm{a}}=100 \mathrm{~min}$ and b) $t_{\mathrm{a}}=24 \mathrm{~h}$; c) Stabilized voltammograms for $\mathrm{Au}(111)$-supported melanin films $(E=-1.0 \mathrm{~V}$, $\left.c=0.03 \mathrm{~g} \mathrm{~L}^{-1}, t_{\mathrm{a}}=40 \mathrm{~h}\right)$ recorded in phosphate buffer $\mathrm{pH} 7$ at $0.02 \mathrm{~V} \mathrm{~s}^{-1}$ from 0.0 to $-0.9 \mathrm{~V}$.

ready reported, ${ }^{[14]}$ these voltammograms show four redox processes with anodic peaks at $-0.40 \mathrm{~V}\left(\mathrm{~A}^{\prime} \mathrm{I}\right),-0.63 \mathrm{~V}(\mathrm{AI})$, $-0.85 \mathrm{~V}(\mathrm{AII})$, and $-1.15 \mathrm{~V}$ (AIII), and cathodic peaks at $-0.43 \mathrm{~V}\left(\mathrm{C}^{\prime} \mathrm{I}\right),-0.73 \mathrm{~V}(\mathrm{CI}),-0.93 \mathrm{~V}(\mathrm{CII})$, and $-1.2 \mathrm{~V}$ (CIII) preceding the hydrogen evolution reaction. All these redox processes are absent in the uncovered Au electrode. Here we have extended the electrochemical characterization to neutral media because it is important for biological applications. The voltammetric features are also observed in phosphate buffer ( $\mathrm{pH}$ 7.0) for thick melanin films, with the exception of peaks AIII/CIII (Figure 6c).

To identify the redox couple corresponding to the Fe-melanin system, we have electropolymerized TAPP- $\left(\mathrm{Fe}^{\mathrm{III}}\right.$ chloride) and iron-free TAPP ${ }^{[16]}$ on $\mathrm{Au}(111)$ substrates. The porphyrin contains octahedrally coordinated $\mathrm{Fe}$ bound to the organic material. The voltammetric response of these films (Figure 7) in $0.1 \mathrm{~m} \mathrm{NaOH}$ exhibits broad anodic current

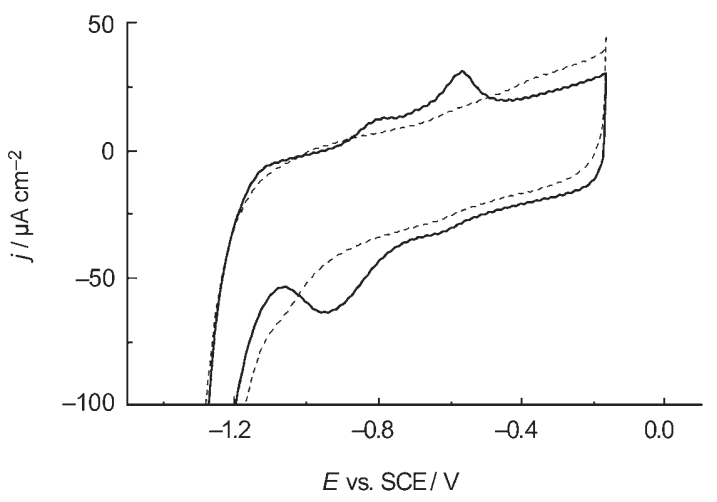

Figure 7. Typical stabilized voltammograms for TAPP (----) and TAPP( $\mathrm{Fe}^{\mathrm{III}}$ chloride) (-) electropolymerized on $\mathrm{Au}(111)$ (300 cycles) recorded in $\mathrm{NaOH}(0.1 \mathrm{M})$ at $0.02 \mathrm{~V} \mathrm{~s}^{-1}$.

peaks in the potential range of -0.6 to $-0.8 \mathrm{~V}$, and broad cathodic ones in the -0.65 to $-0.9 \mathrm{~V}$ range. These voltammetric peaks can be assigned to the $\mathrm{Fe}^{3+} / \mathrm{Fe}^{2+}$ redox couples present in the polymerized porphyrin film. Although a straightforward assignment of voltammetric peaks in the Fe-melanin system is difficult, results from Figures 6a and 7 suggest that $\mathrm{AI} / \mathrm{CI}-\mathrm{AII} / \mathrm{CII}$ peaks in melanin could involve the $\mathrm{Fe}^{3+} / \mathrm{Fe}^{2+}$ redox couple of Fe coordinated to the DHI and DHICA monomers.

On the other hand, the absence of the AIII/CIII peak in acidic media, ${ }^{[14]}$ and also in the phosphate buffer (Figure 6b), suggests that these peaks are related to the redox behavior of the iron oxide nanoparticles trapped in the film. In fact, it has been shown that $\mathrm{Fe}_{2} \mathrm{O}_{3}$ nanoparticles supported on ITO electrodes in phosphate buffer at $\mathrm{pH} 8$ are dissolved in the first scan at $-0.66 \mathrm{~V}$, and yield soluble $\mathrm{Fe}^{2+}$. ${ }^{27]}$

Hydrogen peroxide electrocatalysis: When hydrogen peroxide $(4 \mathrm{~mm}$ ) is added to a $0.1 \mathrm{~m} \mathrm{NaOH}$ solution (Figure $8 \mathrm{a}$ ), the cathodic polarization curve for the Au electrode shows two well-defined current peaks. The first one at $\approx-0.2 \mathrm{~V}$ (peak CA) corresponds to the electroreduction of oxygen to hydrogen peroxide, and the second one at $-1.2 \mathrm{~V}$ (peak $\mathrm{CB}$ ) is related to the electroreduction of hydrogen peroxide to hydroxyls ions. In fact, $\mathrm{Au}$ electrodes reduce $\mathrm{O}_{2}$ in two well-defined steps ${ }^{[28]}$ according to Equations (1) and (2):

$$
\begin{aligned}
& \mathrm{O}_{2}+2 \mathrm{H}_{2} \mathrm{O}+2 \mathrm{e}^{-} \rightleftharpoons \mathrm{H}_{2} \mathrm{O}_{2}+2 \mathrm{OH}^{-} \\
& \mathrm{H}_{2} \mathrm{O}_{2}+2 \mathrm{e}^{-} \rightleftharpoons 2 \mathrm{OH}^{-}
\end{aligned}
$$



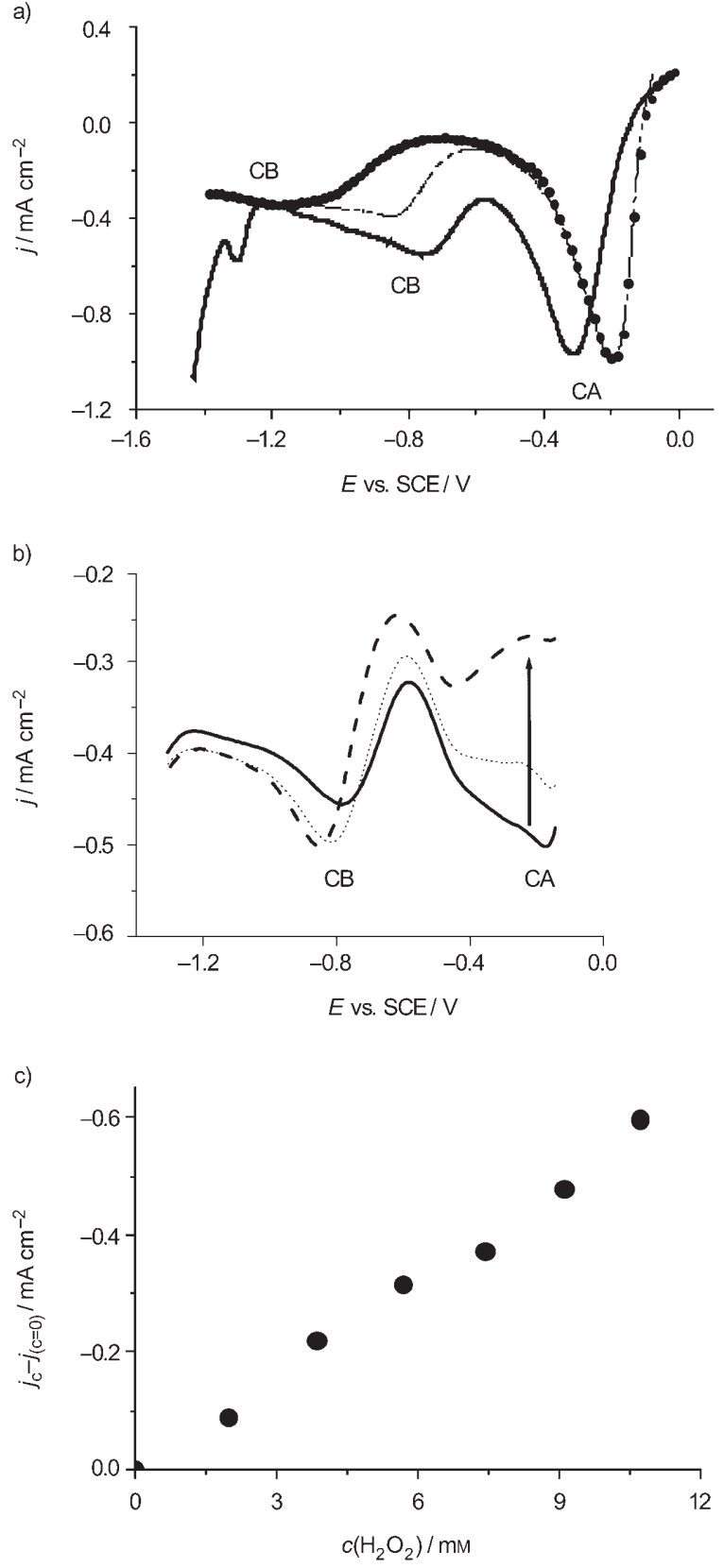

Figure 8. a) Cathodic polarization curves recorded at $0.02 \mathrm{~V} \mathrm{~s}^{-1}$ from 0.0 to $-1.3 \mathrm{~V}$ in $\mathrm{NaOH}(0.1 \mathrm{M})+\mathrm{H}_{2} \mathrm{O}_{2}(4 \mathrm{~mm})$ for $\mathrm{Au}(111)(\bullet)$, melanin-covered $\mathrm{Au}(111)\left(E=-1.0 \mathrm{~V}, t_{\mathrm{a}}=60 \mathrm{~min}, c=0.03 \mathrm{gL}^{-1}\right)(-)$, and melanincovered $\mathrm{Au}(111)\left(E=-1.0 \mathrm{~V}, t_{\mathrm{a}}=60 \mathrm{~min}, c=0.03 \mathrm{gL}^{-1}\right)$ after acid cleaning in $\mathrm{H}_{2} \mathrm{SO}_{4}(0.1 \mathrm{M})$ for $1 \mathrm{~min}(-\cdot-\cdot)$; b) Cathodic polarization curves recorded under the same experimental conditions as those in (a) but with bubbling of $\mathrm{N}_{2}$ into the electrochemical cell for $5(-), 15(\cdots \cdots)$, and 30 min (---). The arrow indicates the decrease in peak $\mathrm{CA}$ with $\mathrm{N}_{2}$ bubbling; c) Stationary current density $j_{c}-j_{(c=0)}$ versus $\mathrm{H}_{2} \mathrm{O}_{2}$ concentration plot for a melanin-covered $\mathrm{Au}(111)$ electrode $\left(E=-1.0 \mathrm{~V}, t_{\mathrm{a}}=100 \mathrm{~min}\right.$, $\left.c=0.3 \mathrm{gL}^{-1}\right) . j_{c}$ is the stationary current density read at $-0.75 \mathrm{~V}$ for the sample, and $j_{(c=0)}$ is the stationary current read at $-0.75 \mathrm{~V}$ for a $\mathrm{H}_{2} \mathrm{O}_{2}-$ free solution.

Similar curves recorded for the melanin-covered $\mathrm{Au}$ electrode show that while peak $\mathrm{CA}$ shifts slightly in the negative direction, peak $\mathrm{CB}$ shifts $\approx 0.5 \mathrm{~V}$ in the positive direction.
We have confirmed that CA corresponds to the reaction ${ }^{[1 \mathrm{a}]}$ by bubbling $\mathrm{N}_{2}$ into the electrochemical cell. In fact, as the bubbling time is increased, the peak CA decreases markedly, while peak CB remains practically unchanged (Figure $8 \mathrm{~b}$ ). We have also demonstrated, from the linear dependence of the stationary current read at $-0.75 \mathrm{~V}\left(j_{c}\right)$ on the hydrogen peroxide concentration (c) (Figure 8c), that peak CB corresponds to the electroreduction of hydrogen peroxide [Eq. (1b)]. In agreement with this conclusion we observed that the $\mathrm{CB}$ peak potential moves slightly in the positive direction as the hydrogen peroxide concentration is increased. The shift of peak $\mathrm{CB}$ from -1.2 to $-0.75 \mathrm{~V}$, shown in Figure 8a when melanin covers the $\mathrm{Au}(111)$ surface, indicates that the film efficiently catalyzes hydrogen peroxide electroreduction. The catalytic effect appears in the potential range where the $\mathrm{Fe}-$ melanin film is electrochemically active (peaks AI/CI).

Note that the current density plotted in Figure 8c corresponds to the electrocatalytic reduction of hydrogen peroxide without any contribution from the current density of the melanin redox couples, because we have subtracted the current density measured in a hydrogen peroxide free solution. After acid cleaning, the catalytic effect is still evident with peak $\mathrm{CB}$ at $\approx-0.8 \mathrm{~V}$, indicating that the $\mathrm{Fe}_{3} \mathrm{O}_{4}$ nanoparticles $^{[29]}$ are not essential in the hydrogen peroxide enhanced electroreduction (Figure 8a).

Similar results were observed for hydrogen peroxide electroreduction in the phosphate buffer (Figure 9). For the $\mathrm{Au}$ electrode a small peak at $-0.20 \mathrm{~V}(\mathrm{CA})$, assigned to oxygen electroreduction, and a wave at $-0.8 \mathrm{~V}(\mathrm{CB})$ assigned to hydrogen peroxide electroreduction, were observed. ${ }^{[30]}$ For the melanin-covered $\mathrm{Au}$ the electrocatalytic effect appears in the $0.0-0.5 \mathrm{~V}$ range where the Au electrode shows negligible activity. After bubbling $\mathrm{N}_{2}$ through the solution, the contribution of both processes is more clearly seen (Figure 9c). In fact, peak CA appears as a hump while peak CB is clearly resolved. Again the hydrogen peroxide electroreduction on the melanin-covered $\mathrm{Au}$ takes place $0.4 \mathrm{~V}$ more positive than on the Au electrode. The fact that the electrocatalytic effect is also observed in phosphate buffer, where the $\mathrm{Fe}_{3} \mathrm{O}_{4}$ nanoparticles are dissolved, ${ }^{[26]}$ confirm our previous observation that these nanoparticles are not essential for hydrogen peroxide electrocatalysis.

In Figure 10, we have compared the electroreduction curves of hydrogen peroxide $(2 \mathrm{~mm})$ in $\mathrm{NaOH}(0.1 \mathrm{~m})$ recorded for melanin-covered, polymerized TAPP- $\left(\mathrm{Fe}^{\mathrm{III}}\right.$ chloride), and polymerized Fe-free TAPP on Au(111) electrodes. While the Fe-free TAPP polymer shows no enhanced electrocatalytic activity for hydrogen peroxide electroreduction, with the current peak $\mathrm{CB}$ at $-1.1 \mathrm{~V}$ (close to that observed for the plain $\mathrm{Au}$ electrode in Figure 8), the $\mathrm{Fe}-$ melanin and Fe-containing TAPP polymer exhibit peak $\mathrm{CB}$ in the range $-0.75-0.85 \mathrm{~V}$. This is good evidence that the electrocatalytic activity of $\mathrm{Fe}-$ melanin is related to $\mathrm{Fe}$-melanin nanoparticles. Note also that the potential of peak CB is slightly more positive and the electrocatalytic current higher for the $\mathrm{Fe}-$ melanin film than for the Fe-porphyrin polymer. Further- 


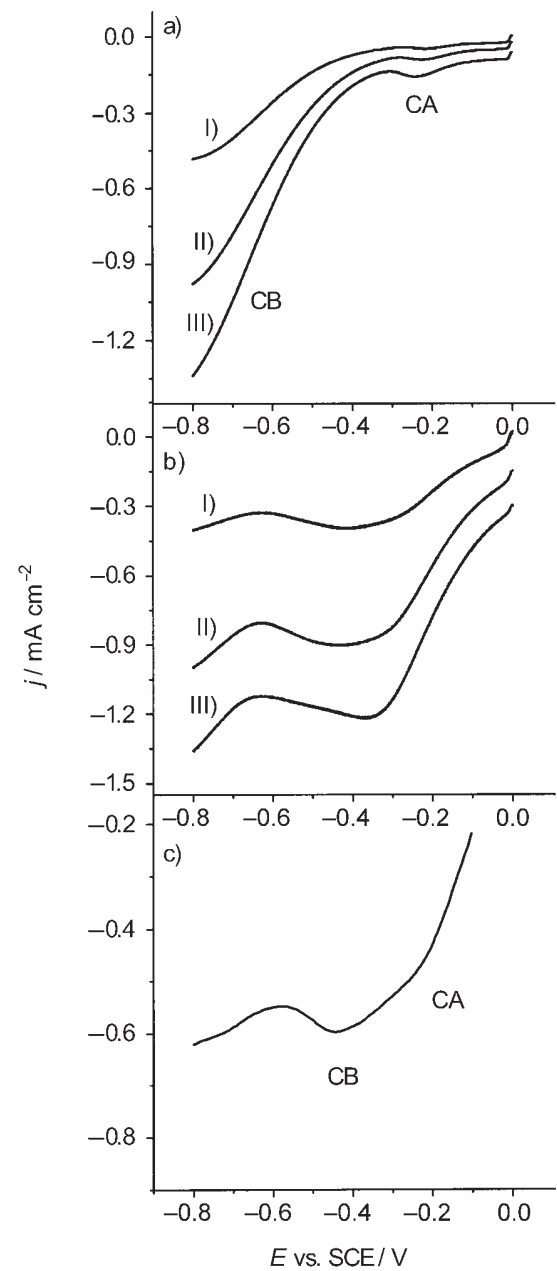

Figure 9. Cathodic polarization curves recorded at $0.02 \mathrm{~V} \mathrm{~s}^{-1}$ from 0.0 to $-0.8 \mathrm{~V}$ for a) $\mathrm{Au}(111)$ and b) melanin-covered $\mathrm{Au}(111)\left(E=-1.0 \mathrm{~V}, t_{\mathrm{a}}=\right.$ $\left.15 \mathrm{~h}, c=0.03 \mathrm{gL}^{-1}\right)$ in phosphate buffer $(\mathrm{pH} 7.0)$ at different $\mathrm{H}_{2} \mathrm{O}_{2}$ concentrations: I) 2.44, II) 4.59 , and III) $6.5 \mathrm{~mm}$; c) Similar cathodic polarization curve for melanin-covered $\mathrm{Au}(111)\left(E=-1.0 \mathrm{~V}, t_{\mathrm{a}}=15 \mathrm{~h}, c=\right.$ $\left.0.03 \mathrm{~g} \mathrm{~L}^{-1}\right)$ in phosphate buffer $(\mathrm{pH} 7.0)+\mathrm{H}_{2} \mathrm{O}_{2}(4.59 \mathrm{~mm})$ after $5 \mathrm{~min} \mathrm{~N}_{2}$ bubbling.

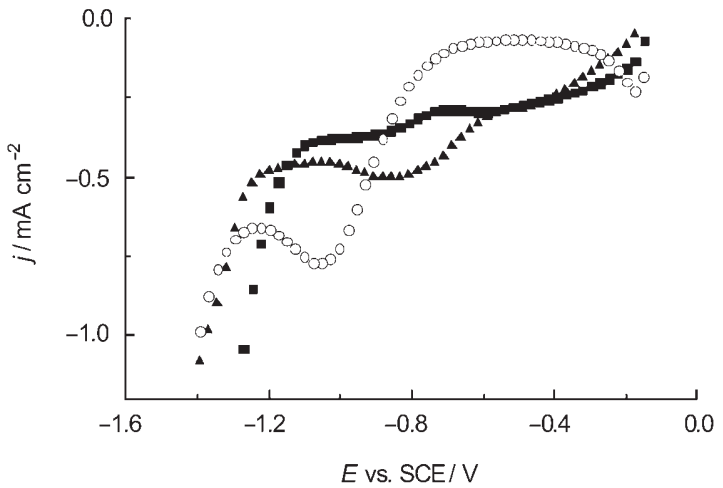

Figure 10. Cathodic polarization curves recorded at $0.02 \mathrm{~V}$ from -0.1 to $-1.4 \mathrm{~V}$ in $\mathrm{NaOH}(0.1 \mathrm{M})+\mathrm{H}_{2} \mathrm{O}_{2}(2 \mathrm{~mm})$. Melanin-covered $\mathrm{Au}(111)(E=$ $\left.-1.0 \mathrm{~V}, t_{\mathrm{a}}=60 \mathrm{~min}, c=0.3 \mathrm{~g} \mathrm{~L}^{-1}\right)(\boldsymbol{\Delta})$, TAPP-(Fe ${ }^{\mathrm{III}}$ chloride) (घ), TAPP (300 cycles) (o) more, the behavior of the melanin film compares [after $\mathrm{pH}$ correction of the peak potential according to Equation (1b)] very well with the electrocatalytic behavior of iron octaethylporphyrin monolayers on $\mathrm{Au}(111)$, as reported in reference [13].

To obtain more evidence about the role of $\mathrm{Fe}$ on the electrocatalytic process, melanin-covered Au was immersed in disodium ethylenediaminetetraacetic acid (EDTA) aqueous solution. It was expected that EDTA not only eliminates the $\mathrm{Fe}_{3} \mathrm{O}_{4}$ nanoparticles from the film, but also eliminates octahedrally coordinated Fe from the melanin. In fact, experimental data have shown that EDTA is able to remove $\mathrm{Fe}$ from $\mathrm{Fe}$-melanin granules in solution without changes in the granule shape. ${ }^{[31]}$

The voltammetric response of a melanin film on $\mathrm{Au}$, recorded in $\mathrm{NaOH}(0.1 \mathrm{M})$ after contact with $\mathrm{NaOH}(0.1 \mathrm{M})$ containing EDTA $(20 \mathrm{~mm})$ for different times, is shown in Figure 11a. It is evident that the voltammetric peaks AIII/
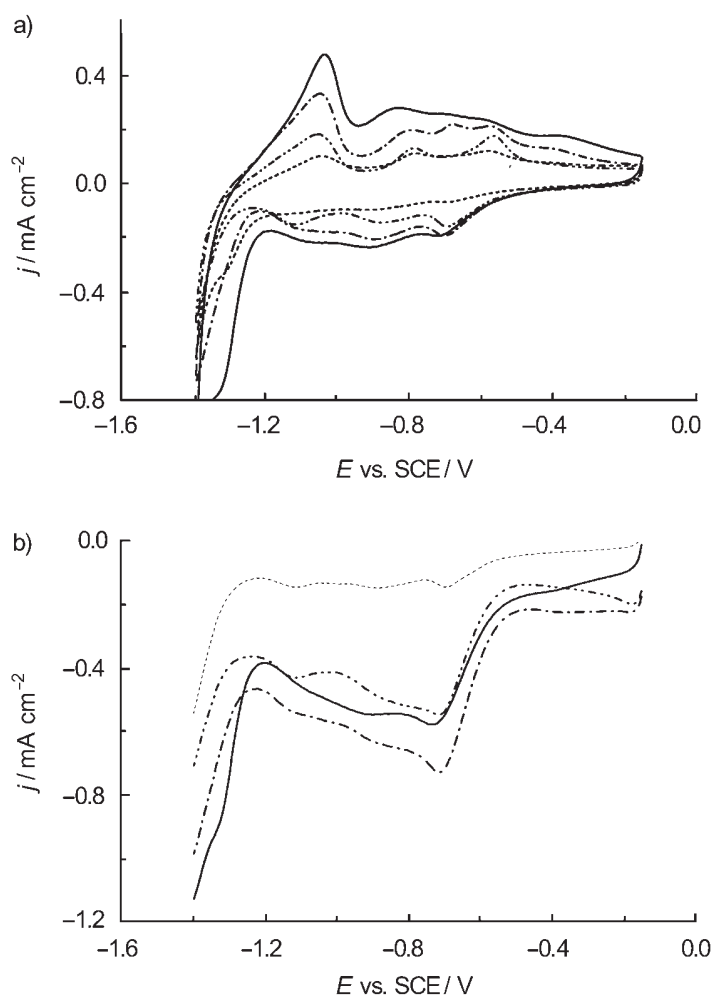

Figure 11. a) Stabilized voltammograms for melanin films $\left(t_{\mathrm{a}}=60 \mathrm{~min}, c=\right.$ $\left.0.3 \mathrm{~g} \mathrm{~L}^{-1}, E=-1.0 \mathrm{~V}\right)$ recorded in $\mathrm{NaOH}(0.1 \mathrm{M})$ at $0.02 \mathrm{~V} \mathrm{~s}^{-1}$ after immersion for different times $(t)$ in EDTA $(20 \mathrm{~mm})$ aqueous solutions; b) Cathodic polarization curves recorded at $0.02 \mathrm{~V}$ from -0.1 to $-1.4 \mathrm{~V}$ in $\mathrm{NaOH}(0.1 \mathrm{M})+\mathrm{H}_{2} \mathrm{O}_{2}$. (2 mM) for the melanin films shown in (a). $t=0$ $(-) ; t=1 \min (-\cdot-\bullet) ; t=10 \min (-\cdot \cdot-\cdot) ; t=20 \min (---)$ for both (a) and (b).

CIII related to the $\mathrm{Fe}_{3} \mathrm{O}_{4}$ nanoparticles are strongly affected, while the other voltammetric peaks show relatively smaller changes.

We conclude that $\mathrm{Fe}_{3} \mathrm{O}_{4}$ nanoparticles are rapidly eliminated, while the Fe coordinated to the melanin nanoparti- 
cles is slowly removed from the film. Accordingly, the electrocatalytic activity shows no marked changes for $\mathrm{Fe}-$ melanin films that have been in contact with the EDTA-containing solutions for immersion times shorter than $10 \mathrm{~min}$ (Figure 11b). In fact, during this period $\mathrm{Fe}_{3} \mathrm{O}_{4}$ is preferentially removed while the content of $\mathrm{Fe}$ in the melanin nanoparticles is only slightly affected. Note that this assumption is supported by AES data (Figure 1), which shows a marked decrease in the oxygen-bound Fe after acid cleaning. In fact, it is well known that magnetite dissolves readily in acid media. ${ }^{[32]}$ On the other hand, for longer immersion times, the $\mathrm{Fe}$ present in the melanin nanoparticles is removed and the electrocatalytic activity is practically eliminated. Voltammetric results (not shown) obtained for Au-supported melanin films, grown from a melanin solution kept in contact with EDTA for six days, show peaks $\mathrm{AI}^{\prime} / \mathrm{CI}^{\prime}$ as the main redox contributions. Therefore, these peaks should be related to the quinone/hydroquinone system.

It should be noted that some loss of melanin granules from the film is also possible during the treatment with EDTA. Recent data have shown that multicharged ions play an important role in assisting, or templating, the assembly of the metal-free organic components to form three-dimensional substructures distributed along the protein scaffold within granules. $^{[31]}$

A possible pathway for the electrocatalytic activity of melanin films, when the Au electrode potential is polarized at $-0.75 \mathrm{~V}$ (peak CB), is shown in Scheme 1. This pathway

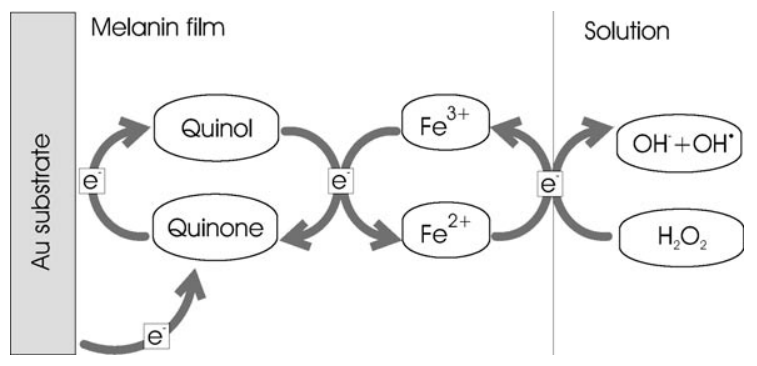

Scheme 1. A possible reaction scheme for the electrocatalytic activity of $\mathrm{Fe}-$ melanin films in the potential region of peak $\mathrm{CB}$.

first involves the oxidation of $\mathrm{Fe}^{2+}$ to $\mathrm{Fe}^{3+}$ (iron-bound melanin) by hydrogen peroxide, which is reduced to $\mathrm{HO}^{-}$ions and $\mathrm{OH}^{-}$radicals, as in the Fenton reaction. Then, $\mathrm{Fe}^{3+}$ is reduced to $\mathrm{Fe}^{2+}$ by quinol groups (in this potential range they are completely reduced), which are oxidized to quinone groups. Finally, the quinone groups can be reduced again to quinol at the electrode surface to complete a catalytic cycle. This scheme is supported by the fact that melanosomes are able to reduce the $\mathrm{Fe}^{\mathrm{III}}$-cytochrome system. ${ }^{[33]}$

\section{Conclusions}

We have prepared nanostructured, ultrathin melanin films supported on $\mathrm{Au}(111)$ by electrochemical self-assembly.
XANES, AES, MFM, and voltammetric data indicate two types of $\mathrm{Fe}$ in the film: $\mathrm{Fe}_{3} \mathrm{O}_{4}$ nanoparticles and $\mathrm{Fe}$-bound melanin nanoparticles. Thus, the system can be described as a nanostructured organic-inorganic composite with magnetic and electrocatalytic properties. In fact, the $\mathrm{Fe}-$ melanin system exhibits electrocatalysis for hydrogen peroxide electroreduction in the potential range in which the film presents redox couples. The main electrocatalytic activity of the film is related to the Fe coordinated to the cathecol units in an octahedral configuration, as concluded by comparison with Fe-containing porphyrin polymers that exhibit a similar activity for hydrogen peroxide electroreduction. Note, however, that the preparation of the melanin film is performed directly in aqueous solutions without the use of organic solvents, as for polymerized Fe-containing porphyrins. However, the magnetic properties are concentrated in $\mathrm{Fe}_{3} \mathrm{O}_{4}$ nanoparticles trapped in the organic matrix.

Results from this work can be important for the preparation of biomimetic systems. In particular, $\mathrm{Fe}-$ melanin films supported on $\mathrm{Au}$ open the possibility to study the influence of melanin structure (film thickness, granule size) on $\mathrm{Fe}$ uptake and storage, and to correlate this information with the peroxidase activity of the Fe-melanin systems. These systems could also be tested in different electrolytes in the presence of other metal cations and complexing substances. The Fe-melanin system supported on $\mathrm{Au}$ electrodes or other metals could also be used for oxygen reduction electrocatalysis, and for oxygen and hydrogen peroxide biosensors, ${ }^{[34]}$ as they exhibit similar activity to $\mathrm{Fe}$ porphyrins. Metal-supported Fe melanins could also be explored as a decontamination system through the production of reactive oxygen species in the presence of hydrogen peroxide. ${ }^{[35]} \mathrm{Fi}-$ nally, it is well known that iron oxide nanoparticles must be coated with biocompatible polymers for biological and medical applications. ${ }^{[36]}$ The interaction of $\mathrm{Fe}_{3} \mathrm{O}_{4}$ nanoparticles with melanin granules in our films suggests that this biopolymer could be a good candidate for these applications.

\section{Acknowledgements}

We are grateful to Spanish MCyT (BQU2002-03249) and MEC (CTQ2005-03222/BQU), and to the Argentinian ANPCyT (PICT0211111 and PICT03-17492) funding. This project was partially supported by LNLS under project D04B-XAFS1-4642. P.D acknowledges a grant from Conicyt-Chile and a fellowship from the MECESUP-REDES project. The authors would like to thank Dr. F. Armijo from Departamento de Química de los Materiales, Facultad de Química y Biología, Universidad de Santiago de Chile, Chile, for his help in the preparation of the Fe-TAPP films.

[1] a) G. Prota in Progress in the Chemistry of Organic Natural Products (Eds.: W. Herr, G. W. Kirby, R. E. Moore, W. Steglich, C. H. Tamm), Springer, New York, 1995, p. 113; b) G. Prota, Pigment Cell Res. 2000, 13, 283-293; c) G. Prota, M elanins and Melanogenesis, Academic Press, San Diego, 1992; d) J. D. Simon, Acc. Chem. Res. 2000, 33, 307-313.

[2] a) C. M. Clancy, J. B. Nofsinger, R. K. Hanks, J. D. Simon, J. Phys. Chem. B 2000, 104, 7871-7873; b) C. M. Clancy, J. D. Simon, Bio- 
chemistry 2001, 40, 133-153; c) Y. Liu, J. D. Simon, Pigment Cell Res. 2003, 16, 72-80.

[3] a) J. M. Menter, I. Willis, Pigment Cell Res. 1997, 10, 10214-10217; b) P. R. Crippa, Coll. Surf. B 2001, 20, 315-319; c) J. E. McGinness, P. Corry, P. Proctor, Science 1974, 183, 853-854.

[4] a) M. D. Rubianes, G. A. Rivas, Anal. Lett. 2003, 36, 329-345; b) S. Gidanian, P. J. Farmer, J. Inorg. Biochem. 2002, 89, 54-60; c) K. B. Stark, J. M. Gallas, G. W. Zajac, J. T. Golab, S. Gidanian, T. McIntire, P. J. Farmer, J. Phys. Chem. B 2005, 109, 1970-1977; d) S. Subianto, G. Will, P. Meredith, Polymer 2005, 46, 11505-11509.

[5] a) Y. Liu, V. Kempf, A. Samokhvalov, J. D. Simon, Pigment Cell Res. 2003, 16, 608-618; b) B. Szpoganicz, S. Gidanian, P. Kong, P. Farmer, J. Inorg. Biochem. 2002, 89, 45-53.

[6] a) L. Zecca, F. A. Zucca, P. Costi, D. Tampellini, A. Gatti, M. Gerlach, P. Riederer, R. G. Fariello, S. Ito, M. Gallorini, D. Sulzer, J. Neural Transm. Suppl. 2003, 65, 145-155; b) B. A. Faucheux, M. E. Martin, C. Beaumont, J. J. Hauw, Y. Agid, E. C. Hirsch, J. Neurochem. 2003, 86, 1142-1148.

[7] a) S. Aime, B. Bergamasco, D. Biglino, G. Digilio, M. Fasano, E. Giamello, L. Lopiano, Biochim. Biophys. Acta 1997, 1361, 49-58; b) A. J. Kropf, B. A. Bunker, M. Eisner, S. C. Moss, L. Zecca, A. Stroppolo, P. R. Crippa, Biophys. J. 1998, 75, 3135-3142; c) F. Bolzoni, S. Giraudo, L. Lopiano, B. Bergamasco, M. Fasano, P. R. Crippa, Biochim. Biophys. Acta 2002, 1586, 210-218; d) L. Zecca, D. Tampellini, M. Gerlach, P. Riederer, R. G. Fariello, D. Sulzer, J. Clin. Pathol. 2001, 54, 414-418.

[8] a) W. Korytowski, T. Sarna, J. Biol. Chem. 1990, 265, 12410-12416; b) M. Gerlach, K. L. Double, D. Ben-Shachar, L. Zecca, M. B. Youdim, P. Riederer, Neurotoxic. Res. 2003, 5, 35-44; c) S. Husain, S. M. Hadi, Mutat. Res. 1998, 397, $161-168$; d) P. J. Farmer, S. Gidanian, B. Shahandeh, A. J. Di Bilio, N. Tohidian, F. L. Meyskens, Jr., Pigment Cell Res. 2003, 16, 273-279.

[9] K. C. Littrell, J. M. Gallas, G. W. Zajac, P. Thiyagarajan, Photochem. Photobiol. 2003, 77, 115-120.

[10] a) B. Pilas, T. Sarna, B. Kalyanaraman, H. M. Swartz, Free Radical Biol. Med. 1988, 4, 285-293; b) T. Shima, T. Sarna, H. M. Swartz , A. Stroppolo, R. Gerbasi, L. Zecca, Free Radical Biol. Med. 1997, $23,110-119$.

[11] a) A. Deisseroth, A. L. Dounce, Physiol. Rev. 1970, 50, 319-375; b) E. Cadenas, BioFactors 1997, 6, 399-402.

[12] R. S. Sohal, Mech. Ageing Dev. 1991, 60, 189-198.

[13] S. Yoshimoto, A. Tada, K. Itaya, J. Phys. Chem. B 2004, 108, $5171-$ 5174.

[14] P. Díaz, Y. Gimeno, P. Carro, S. González, P. L. Schilardi, G. Benítez, R. C. Salvarezza, A. Hernández Creus, Langmuir 2005, 21, 5924-5930.

[15] a) T. W. Capehart, J. F. Herbst, F. E. Pinkerton, Phys. Rev. B 1995 52, 7907-7914; b) I. Arcon, B. Mirtic, A. Kodre, J. Am. Ceram. Soc. 1998, 81, 222-224; c) J. Wong, F. W. Lytle, R. P. Messmer, D. H. Maylotte, Phys. Rev. B 1984, 30, 5596-5610; C. Pak, G. L. Haller, Microporous Mesoporous Mater. 2001, 48, 165-170; T. Ressler, J.
Wong, J. Roos, J. Synchrotron Radiat. 1999, 6, 656-658; G. Kataby, Y. Koltypin, J. Rothe, J. Hormes, I. Felner, X. Cao, A. Gedanken, Thin Solid Films 1998, 333, 41-49; M. Fernández-García, Catal. Rev. Sci. Eng. 2002, 44, 59-121; d) R. E. Watson, M. L. Perlman, J. F. Herbst, Phys. Rev. B 1976, 13, 2358-2365; P. S. Bagus, G. Pacchioni, C. Sousa, T. Minerva, F. Parmigiani, Chem. Phys. Lett. 1992, 196, 641-646.

[16] M. Lucero, G. Ramírez, A. Riquelme, I. Azocar, M. Isaacs, F Armijo, J. E. Förster, E. Trollund, M. J. Aguirre, D. Lexa, J. Mol. Catal. A 2004, 221, 71-76.

[17] M. B. Clark, J. A. Gardella, Jr., J. M. Schultz, D. G. Patil, L. Salvati, Jr., Anal. Chem. 1990, 62(9), 949-956.

[18] R. Weissmann, K. Muller, Surf. Sci. Rep. 1981, 1, 251-309.

[19] A. J. Kropf, B. A. Bunker, M. Eisner, S. C. Moss, I. Zecca, A. Stroppolo, P. R. Crippa, Biophys. J. 1998, 75, 3135-3142.

[20] P. J. Durham in X-ray Absorption: Principles, Applications, Techniques of EXAFS, SEXAFS and XANES (Eds.: D. C. Koningsberger, R. Prins), Wiley, New York, 1988.

[21] J. M. Ramallo-López, E. J. Lede, F. G. Requejo, J. A. Rodriguez, J.Y. Kim, R. Rosas-Salas, J. M. Domínguez, J. Phys. Chem. B 2004, 108, 20005-20010.

[22] R. G. Shulman, Y. Yafet, P. Eisenberger, W. E. Blumberg, Proc. Natl. Acad. Sci. USA 1976, 73, 1384-1388.

[23] A. L. Roe, D. J. Schneider, R. J. Mayer, J. W. Pyrz, J. Widom, L. Que, Jr., J. Am. Chem. Soc. 1984, 106, 1676-1681.

[24] K. O. Hodgson, J. Am. Chem. Soc. 2000, 122, 5775-5787; T. E. Westre, P. Kennepohl, J. G. DeWitt, B. Hedman, K. O. Hodgson, E. I. Solomon, J. Am. Chem. Soc. 1997, 119, 6297-6314.

[25] A. Samokhvalov, Y. Liu, J. D. Simon, Photochem. Photobiol. 2004, $80,84-88$

[26] Y. S. Kang, S. Risbud, J. F. Rabolt, P. Stroeve, Chem. Mater. 1996, 8, 2209-2211.

[27] K. J. McKenzie, F. Marken, Pure Appl. Chem. 2001, 73, 1885-1894.

[28] M. R. Tarasewich, A. Saskowski, E. Yeager in Comprehensive Trea tise of Electrochemistry, Vol. 7 (Eds.: B. E. Conway, J. O'M. Bockris, E. Yeager, S. U. N. Khan, R. T. White), Plenum Press, New York, 1983, Chapter 6, p. 361

[29] E. R. Vago, E. J. Calvo, J. Electroanal. Chem. 1992, 339, 41-67.

[30] M. S. El-Deab, T. OKajima, T. Ohsaka, J. Electrochem. Soc. 2003, 150, A851-A857.

[31] Y. Liu, J. D. Simon, Pigment Cell Research 2005, 18, 42-48.

[32] G. Senanayake, G. K. Das, Hydrometallurgy 2004, 72, 59-72.

[33] A. Samokhvalov, L. Hong, Y. Liu, J. Garguilo, R. J. Nemanich, G. S. Edwards, J. D. Simon, Photochem. Photobiol. 2005, 81, 145.

[34] G. Ashkenasy , A. Ivanisevic, R. Cohen, C. E. Felder, D. Cahen, A. B. Ellis, A. Shanzer, J. Am. Chem. Soc. 2000, 122, 1116-1122.

[35] P. Huston, J. J. Pignatello, Water Res. 1999, 33, 1238-1246.

[36] S. Yu, G. M. Chow, J. Mater. Chem. 2004, 14, 2781-2786.

Received: April 6, 2006 Published online: September 29, 2006 